\title{
O PARQUE COMO ESPAÇO EXCLUDENTE E AS FRONTEIRAS INVISÍVEIS: CASO DO ECO PARQUE.
}

\author{
Samantha Busnello \\ Universidade Federal do Paraná. \\ arqsamanthabusnello@gmail.com
}

\section{RESUMO}

Há apropriações do espaço público que, tornam-se parte integrante da vida da própria cidade reproduzindo as relações sociais nela vivida, inclusive a exclusão social. Nesse contexto a análise desse trabalho se concreta no espaço urbano como agente excludente, especificamente observando os conflitos internos entre os usuários um parque urbano. A escolha do parque é baseada na diversidade de agentes que apropriam se do espaço, reproduzindo a diversidade social encontrada na metrópole e com ela seus conflitos. Conclui ao observar um determinado espaço público que as interações entre grupos sociais problematiza a determinação do espaço. Desta forma as barreiras invisíveis são traçadas pelos conflitos criados entre pontos de encontro entre as apropriações por diferentes grupos sociais e os deslocamentos sucessivos.

Palavras-chave: espaço público, parque urbano, conflitos sociais.

\section{ABSTRACT}

There is welcome as part of the life of the city itself reproducing as social relations in it, including social exclusion. In this context the analysis of the work is concrete in the urban space as excluding agent, specifically observing the internal conflicts between the users an urban park. A choice of the park and a diversion of agents that define the space, reproducing a social diversity found in the metropolis and with its conflicts. Conclude the attention and determine the public space as the interactions between social groups problematize the determination of space. In this way as invisible barriers are traced by conflicts created between points of encounter between the different social parts and the successive displacements.

Keywords: public space, urban park, social conflicts. 


\section{INTRODUÇÃO}

O espaço público analisado como espaço físico é parte integrante da vida da cidade reproduzindo as relações da sociais nela dívida. Esses processos são entendidos como naturais baseados na percepção da realidade urbana calcada em ideias construídas socialmente e não na reflexão sobre o real campo de lutas e conflitos que é a cidade. Compreender a apropriação como um conflito resultante da exclusão social requer uma observação mais profunda, baseada na relação dos agentes ocupantes desse espaço. Nesse contexto essa pesquisa busca analisar o espaço público urbano como local de conflitos sociais que resultam na exclusão social.

A justifica de escolher um parque urbano para analisar os conflitos sociais e consequentemente a exclusão de algumas parcelas da população manifesta se de analisar a ideia utópica do espaço público ser abrangente e democrático versus a realidade do espaço ser excludente. Surge a necessidade de compreender as origens e características desses conflitos. Fatores como gerenciamento do espaço, infraestrutura e mobiliários empregados no local, grupos sociais que o frequentam serão analisados para compreender a origem dos conflitos.

Nesse cenário os conflitos e barreiras invisíveis dentro do Eco Parque, reproduzem de forma sintética as relações de exclusão vividas na cidade como um todo. A análise unicamente do espaço público que ao inverter seu papel de democrático de abranger toda a sociedade cria a exclusão social indica através da compreensão dos conflitos parâmetros para retificar o espaço físico e gerenciamento com a finalidade de torná-lo mais inclusivo e atenuas os limites invisíveis e exclusão praticados no parque.

\section{DISCUSSÃO TEÓRICA}

\subsection{Conflitos no espaço público}

Entendemos o espaço público como o espaço que se institui pela diferença entre os membros da sociedade, embasado em relações que envolvem a igualdade de direitos dos indivíduos, traduzido na política social reproduzida dentro da cidade (JOVCHELOVITCH, 2000). O espaço público sinteticamente deveria abranger todos os grupos e atores sociais, entretanto a isonomia de direitos é algo utópico dentro deste universo, pois dentro da nossa sociedade atual a desigualdade é intrínseca e reflete na produção de um espaço público de diferenças e conflitos sociais.

Sendo o espaço público uma construção social refletida da necessidade de sociabilidade dos homens é compreendido por alguns autores, como Santos (2004) tal qual um produto pois é assimilado a, a partir de seu valor de uso, a característica de troca. O parque urbanos geralmente influenciam no seu entorno pois agregam valor a empreendimentos imobiliários, as empresas, a implantação de órgãos públicos. Nesse cenário se constrói um processo segregacionista dentro dos espaços públicos pois o mesmo valor de uso que é agregado a ele promove uma seleção e classificação de usuários. (Carmona, 2003; Santos 2004), Segundo Carmona, as críticas aos espaços públicos estão frequentemente baseadas: "[...] em uma noção idealizada do espaço público como um cenário aberto e inclusivo para a interação social, a ação política e a troca cultural. Embora estes sejam antecedentes históricos distintos para tais qualidades, também é, provavelmente, verdade dizer que o espaço público tenha raramente, se alguma vez, adquirido tal estado de utopia, até porque o público no espaço público não é um grupo coerente e unificado, mas sim uma sociedade fragmentada de grupos de diferentes extratos socioeconômicos (e muitas vezes cultural), divididos por idade e sexo. Cada parte desta sociedade diversificada vai se relacionar com o espaço público de maneira diferente e complexa, buscando objetivos distintos e, por vezes incompatíveis (CARMONA, 2012, p. 1, tradução livre)."

O espaço público geralmente é administrado pelo Estado ou privatizado pelo mesmo para o setor privado. A gestão do espaço, falta ou super gestão, reflete na produção social e nos conflitos gerados no mesmo, Carmona(2012) cita que a vida social nos espaços existe hoje em dia, principalmente onde ela tem sido administrada para conseguir sobreviver. Não é o espaço em si que cria os conflitos, e nem o fato da gestão ser pública ou privada, mas a sim a forma como é gerenciado o acesso e uso ao espaço público, Santos (2004) cita que a gestão pode expressar a contradição entre uma socialização relativa e a exclusão por fatores econômicos e culturais de muitos grupos sociais que ocupam a cidade mas que não podem usar as suas ofertas nem tem ao seu alcance as liberdades potenciais que são de fato negadas a muitos. 
Ao observar um determinado espaço público é possível denotar regiões e interações entre grupos sociais, quais estão presentes, quais estão excluídos e observar os próprios conflitos entre os usuários do espaço. Logo o que problematiza a determinação dos conflitos sociais do espaço são o conjunto dos atores e grupos sociais envolvidos, a gestão do lugar que influência socialmente e fisicamente no uso e apropriação do espaço e o contexto social no qual está aplicado. Os conflitos sociais gerados no espaço público resultam em problemas para os atores desse lugar, para o entorno e para a cidade como um todo, portanto as estratégias de gerenciamento desses espaços deveriam ser voltadas para a inclusão de todos os grupos sociais.

\subsection{Espaço público excludente}

A principal consequência dos conflitos sociais dentro do espaço público é a exclusão social de uma parcela significativa de atores que deixam de participar e desfrutar da infraestrutura e dinâmicas relativas aos locais por inúmeros motivos. Carmona (2003), retrata o espaço de exclusão como uma série de fatores diretamente relacionada a qualidade dos espaços, para ele "Se o espaço é mal gerido e declina fisicamente, se não oferece oportunidades e atividades sociais, culturais, políticas, econômicas, há um declínio social que afasta as pessoas. Pela sua visão a exclusão social promove o declínio do espaço público como um todo "se as pessoas usam menos espaço, então há menos incentivo para fornecer novos espaços e manter os existentes. Com um declínio em sua manutenção e qualidade, os espaços públicos são menos propensos a serem usados, exacerbando assim a espiral viciosa do declínio "(Carmona et al., 2003, p. 111, tradução livre)".

O autor Carmona (2003) classifica os espaços de exclusão de acordo com as suas características e motivos. Para o autor os espaços de desativação são aqueles em que a qualidade física do espaço público interfere na seleção dos usuários. Para alguns atores a qualidade da infraestrutura e acessibilidade será mais importante do que para outros, especificamente para os que apresentam dificuldade de locomoção e limitação de movimentos, usuários com crianças pequenas e idosos. As barreiras físicas podem ser grandes obstáculos para o uso do espaço público e ser um fator extremamente segregador ao não atender todos os usuários, fator que acaba selecionando os grupos que frequentam esses espaços, tornando o espaço público desativável quando não precisa ser, (Imrie \& Hall, 2001, P. 10).

O espaço segregado é aquele que por algum fator, entre poucas variedades de uso do espaço e marginalização da área (medo de crimes e violência no lugar) culminam na evasão do domínio público. Esses espaços apresentam segregação espacial das atividades e a ocupação das áreas dívidas por classe social, idade ou etnia. Segundo Blakely \& Snyder (1997) essa produção de espaço é uma tendência globalizada que reflete o desejo dos grupos predominantes na sociedade movidos pelo desejo de serem vistos como exclusivos ou simplesmente por medo da violência.

A gestão dos espaços públicos por vezes também influência nos processos de segregação, segundo Carmona (2003), quando a gestão gira em torno da ideia do espaço público mercantilizado a noção de espaço público se deteriora face ao espaço privado. Enfatiza que as públicas voltadas segurança dos espaços públicos aumentaram significativamente a partir da década de 80 , fenômeno que denomina de "supergerenciamento". Esse supergerenciamento culmina em estratégias de concepção e gestão que podem ser usadas para excluir determinados grupos e favorecer outros, ou seja, uma prática sutil que envolve pistas visuais com a finalidade de comunicar que apenas aqueles com as qualidades de usuários são aceitos como atores destes espaços, e que aqueles que não se enquadram nesta categoria serão tratados com desconfiança, ou mesmo fisicamente barrados. (Carmona 2003).

O espaço quando é muito cercado por sistemas de segurança não produz apenas segurança, produz também uma segregação praticando a exclusão dos atores indesejáveis, que por vezes são apenas pessoas que não condizem com o "status" do espaço físico e promovem o controle dos "outros" que lá frequentam é rigoroso e direciona as práticas de uso. Carmona cita que não há nada de errado em ajudar as pessoas a se sentirem seguras e protegidas contudo a segregação pode surgir, por exemplo, quando os proprietários e gerentes utilizam do privilégio de proprietários para excluir aqueles que não poderiam ser excluídos dos espaços das cidades, ou de impor códigos de comportamento que vão além das normas sociais (CARMONA; WUNDERLICH, 2012,).

O autor Minton (2006) descreve o potencial de exclusão como resultado do tipo de gerenciamento, para o autor o supergerenciamento produz "Pontos quentes", que dentro do espaço urbano são usados por atores com um potencial financeiro maior. A falta de gerenciamento, ou ainda lugares com uma gestão mais relapsa segundo o autor são denominados "Pontos frios", onde os socialmente excluídos frequentam. Por essa análise, a gestão do espaço público está criando uma realidade urbana de polarização social. Para Murphy (2001) as práticas de exclusão refletidas por essa polaridade provem de políticas públicas com o objetivo de combater as atividades sociais indesejáveis, que influenciam na escolha de usos para os espaços públicos. 
Observa se também a exclusão feita pelos próprios usuários dentro do espaço público, DUNEIER (2000) disserta sobre esse processo de formação de Manchas e Circuitos nos espaços públicos. Manchas tratamse de áreas contíguas do espaço urbano dotadas de equipamentos que marcam seus limites e viabilizam uma atividade ou uma prática dominante enquanto Circuito designa o exercício de uma prática ou oferta de espaços e equipamentos, que não mantém entre si uma relação de contiguidade espacial. Dessa forma a sociabilidade ou exclusão nos espaços públicos surge do conflito entre manchas e circuitos com finalidades diferentes disputando o mesmo espaço.

A concepção idealizada do espaço público como um palco aberto e inclusivo para todas as relações sociais, englobando a ação política e intercâmbio cultural entre todos os atores da sociedade segundo Carmona (2003) é utópica. Para o autor é provavelmente verdadeiro dizer que o espaço público tem raramente, ou nunca, conseguido chegar a tal estado. Em uma sociedade fragmentada o espaço público e seus conflitos traduzidos na exclusão social nada mais é do que uma reprodução das relações de uma sociedade diversificada e excludente. Para o autor os responsáveis pelo design, desenvolvimento e gestão do espaço público contemporâneo permitem nas políticas públicas e consequentemente nos espaços físicos a criação da exclusão ao permitir que as barreiras físicas e psicológicas medo do" outro a dominar estratégias de design de espaço e de gestão pública ao mesmo tempo em que criam o espaço segregado seguindo o desejo de alguns grupos economicamente favorecidos, separado do resto da sociedade refletindo um medo do crime e simplesmente o desejo de ser exclusivo.

\subsection{Parque urbano como espaço excludente}

O parque urbano atualmente é uma das possíveis formas de encontrar o equilíbrio entre o processo de urbanização e a preservação do meio ambiente. As funções de uso, conceitos de projeto e inserções sociais dessa tipologia de espaço público não apresentam um padrão único. LAMAS, cita que estas estruturas verdes são reconhecidas como elementos identificáveis na estrutura urbana. Caracterizam a imagem da cidade; têm individualidade própria; desempenham funções precisas: são elementos de composição e do desenho urbano; servem para organizar, definir e conter espaços.

O parque urbano um é equipamento que teoricamente deve ser um espaço democrático na sua essência, em sua elaboração, construção, em seu gerenciamento e principalmente em seu uso pela sociedade. É a expressão de espaço público físico de muitas cidades, com todos os seus conflitos, divisões, interesses, que deveria possibilitar a integração social e diversidade humana. "O espaço público é, antes de tudo, o lugar, praça, rua, praia, qualquer tipo de espaço onde não haja obstáculos à possibilidade de acesso e participação de qualquer tipo de pessoa, dentro de regras de convívio e debate. Assim, paradoxalmente, embora o espaço público possa ser também o lugar das indiferenças, ele caracteriza-se, na verdade, pela submissão às regras da civilidade. (SUN ALEX, 2008, p. 12)." Contudo como espaço público o parque urbano é palco para conflitos sociais e consequentemente a exclusão social se tornando um potencial espaço excludente.

Observando os agrupamentos sociais e usuários de praças e parques, Alex (2008) entende que o convívio social no espaço público está intimamente relacionado às oportunidades de acesso e uso, a repercussão desta relação na apropriação do espaço no cotidiano identifica se uma série de limites invisíveis que propagam a segregação social. Em sua pesquisa o autor demonstra que as distinções que são construídas ao longo do tempo e entre grupos sociais antagônicos são reproduzidas no cotidiano dos espaços públicos, especificamente em praças e parques.

Para Alex (2008), os grupos sociais diferentes se cruzam em função dos deslocamentos, da mobilidade e do uso no espaço da praça e parques, contudo a aproximação espacial de agentes ou grupos profundamente distantes não representa uma aproximação social. Os grupos podem estar próximos fisicamente, mas a distância social permanece gerando uma série de desconfortos que culmina na exclusão dos atores menos favorecidos pelo espaço do parque urbano.

Os limites invisíveis observados na apropriação de um parque, como em todo espaço público, são criados a partir das dinâmicas cotidianas, é possível denotar fronteiras intangíveis articulando se conforme as diferentes relações emergem no tempo e no espaço entre grupos sociais. Esses limites são identificados como resultados dos conflitos identificados no espaço público ocupado, construindo uma relação de exclusão e segregação através de elementos físicos e sociais que promovam a diferença, a diversidade, a igualdade ou desigualdade.

Nesse sentido compreende se o parque como um espaço que com o intuito de ser democrático e acessível a todas parcelas sociais da cidade acaba criando a exclusão por fatores intrínsecos a sociedade. Corresponde à realidade física e social urbana transcorrendo as diferenças sociais e conflitos correspondentes em todos os espaços públicos.

\section{METOLOGIA}


A pesquisa empregada para entender o Eco Parque como espaço excludente foi do tipo quantitativasdescritivas. Trata-se de uma investigação empírica, com o objetivo de conferir hipóteses. É uma pesquisa quantitativa, que usa técnicas de coleta de dados: entrevistas, sequencias fotográficas, mapeamentos.

Para compreender os conflitos existentes no espaço público a observação de forma direta no local como usuário foi a escolhida pois segundo Zeisel (2006) estar no local permite que os pesquisadores ajustem suas observações a um cenário particular e a uma compreensão refinada da situação". A tipologia de ator participante do espaço usada para a observação foi a de Participante Pleno, pois como frequentador usual e reconhecido do local o pesquisador apresenta minucia em compreender as dinâmicas do espaço. A observação direta de forma dinâmica foi utilizada para compreender o que a arquitetura comportamental chama de Relações entre Ambiente Construído e Comportamento Humano - RAC. Dessa forma além de um amplo estudo e analise do espaço físico do parque para perceber questões fundamentais como: quais o efeitos colaterais que o ambiente tem nas relações entre indivíduos e grupos e como o ambiente físico interfere no comportamento das pessoas. Zeisel (2006)

Socialmente a percepção das relações entre os atores compreendeu perceber quem são os usuários do espaço, como apropriam o parque, quais atividades se relacionam e como estas afetam os outros atores que estão presentes no local. Compreender como a relação entre os usuários provoca mudanças no comportamento, qual o papel do parque na vida desses agentes, observar padrões e regularidade de comportamento dentro dos lugares de ocupação, Zeisel (2006) Além de compreender as percepções físicas, audição, visão, olfato, táctil, dos usuários com o local, notou se quais os sentidos afastam e aproximam os usuários entre si, Pallasma (2006). Seguindo as diretrizes de Zeisel elencou se o seguinte padrão para entender quem são os atores que estão nesse espaço:

Ator ou usuário: Sujeito de uma observação comportamental.

Grupo social: pessoas com padrão de comportamento semelhante no espaço

Ação: definição do nível de abstração para descrever o comportamento e como se distingue os atos individuais e atos de uma sequência conectada.

As técnicas usadas para identificar os atores e seu comportamento no espaço foram empregadas em diferentes dias e horários para construir um espaço amostral amplo e rotineiro do uso do local. Foi usada a Captura fotográfica com câmera de celular e uma câmera sem profissional em sequencias objetivando capturar sutilezas e detalhes, que os olhos do observador não notam. Confecção de mapas observando em planos de diferentes níveis, traduzindo a ideia de como o espaço inteiro é usado unicamente, registrando as sequências de comportamento, escolha de caminhos e localizações fisicas no parque. Por fim a aplicação de questionários buscando compreender a percepção do ator quanto ao espaço público escolhido e como este afeta sua apropriação do espaço.

\section{ESTUDO DE CASO, APRESENTAÇÃO E ANÁLISE}

\subsection{Estudo de Caso: Eco Parque}

O Eco Parque é um dos três parques públicos do município de Chapecó, no estado de Santa Catarina, se localiza na principal avenida da cidade, a Avenida Getúlio Vargas, em frente ao $2^{\circ}$ Batalhão da Polícia Militar. O Conceito do parque é voltado para a prática de exercícios físicos especificamente a caminhada, o local também apresenta espaço de academia aberta, parque infantil, palco de apresentações, anfiteatro, coretos e banheiros públicos.

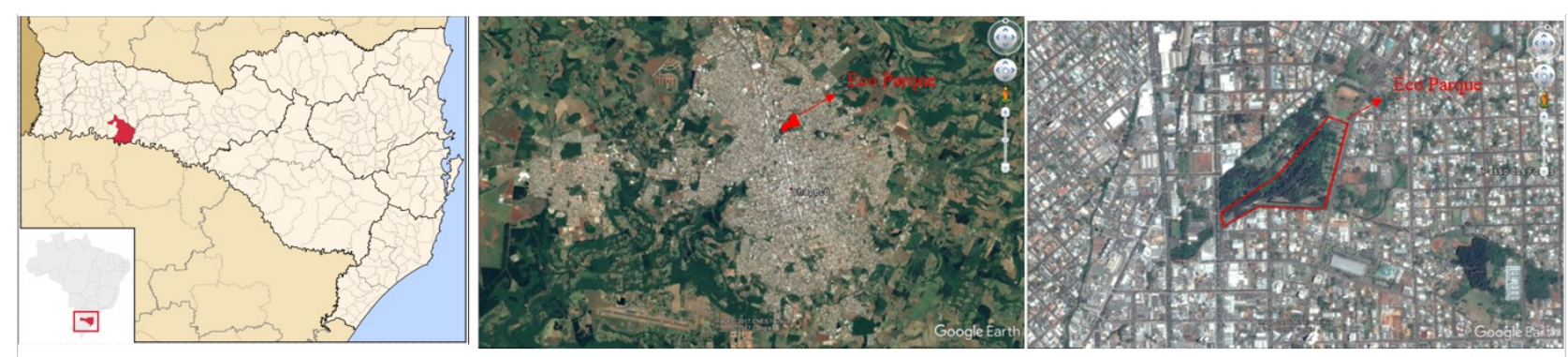

Localização do Eco Parque na cidade de Chapecó

Fonte: Google Earth 2017, modificação: Samantha Busnello, 2017.

Localizado em uma área de preservação permanente, o parque conta com um rio na sua extremidade sul, uma lagoa na área central algumas áreas de banhado. Com uma área de 42.180,00 metros quadrados, possui uma série de restrições sobre o seu uso, paradoxalmente ao conceito de parque para o uso para 
prática de esportes atualmente é proibido andar de bicicleta, patins, patinete ou skate dentro do parque, bem como é proibida a entrada de animais, bolas limitando seu uso.

Após reforma em 2014, o Eco Parque ganhou sinalização e iluminação adequados para utilização noturna pela comunidade. $O$ horário de funcionamento é 6 horas às 21 horas e o parque é cercado e conta com duas guaritas com guarda 24 horas nas suas duas entradas. O gerenciamento do espaço é feito pela Prefeitura Municipal de Chapecó, sem interferência privada, que mantêm o espaço com verba pública.

O conceito do parque é a prática de esportes, contudo por questões como gerenciamento, espaço limitado e topografia as únicas três modalidades de esportes incentivadas dentro do parque é a caminhada, corrida e ginástica aeróbica. Paradoxalmente ao conceito do parque modalidades como ciclismo, skate e patins são proibidas. Alguns usos normais a outros parques como a permanência de animais de estimação também são proibidos.

No parque além da pista de caminhada/corrida há uma academia ao ar livre para a prática de ginástica aeróbica e um parque infantil. Há dois espaços para apresentação de shows, um anfiteatro aberto na parte leste e outro palco junto com uma área de exposições para feiras e realização de eventos na face oeste do parque, esses dois espaços ficam próximos as guaritas e os acessos ao parque, um pela Avenida Getúlio Vargas e outro pela rua Jonh Kenneddy.

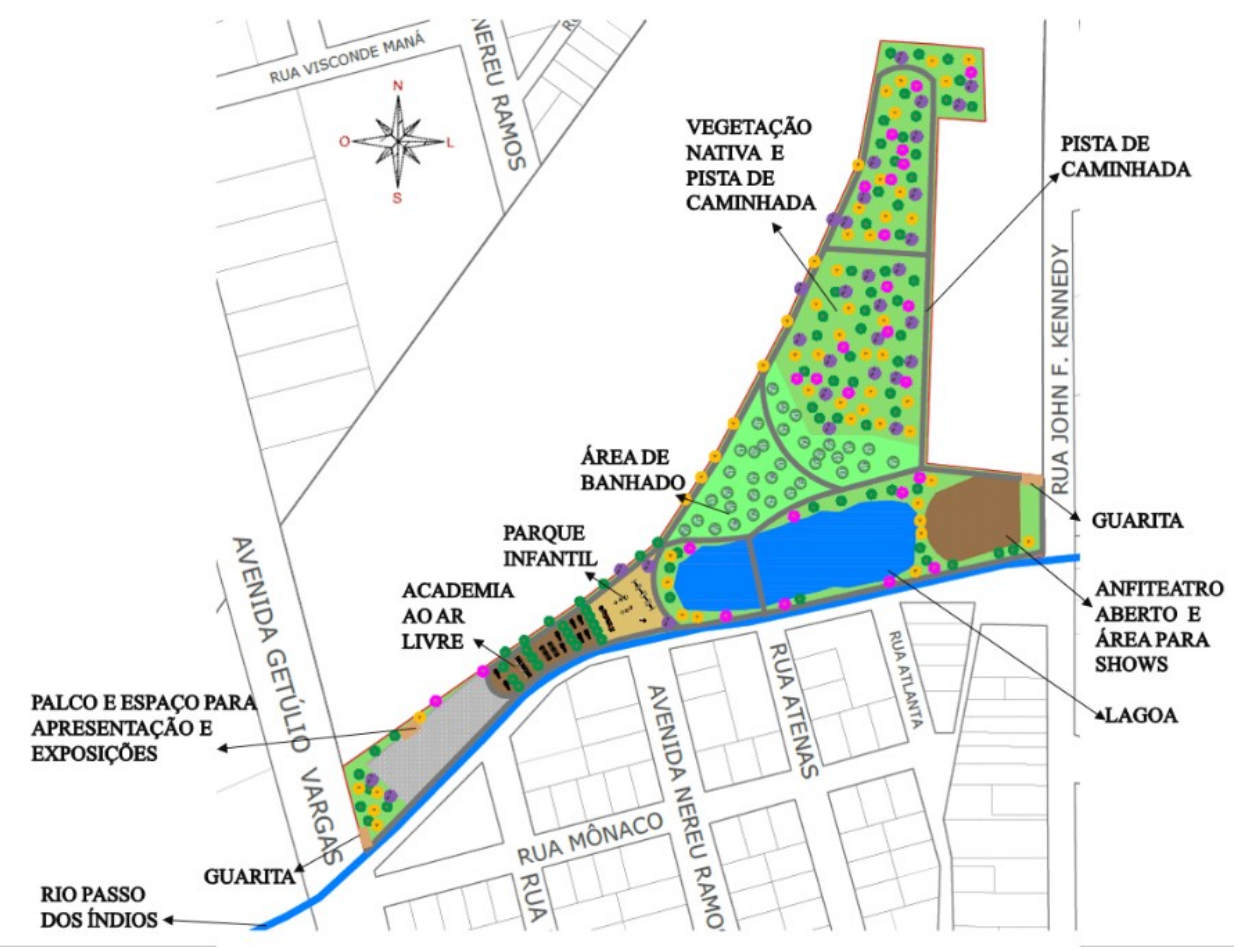

Implantação do parque.

Fonte: Prefeitura Municipal de Chapecó, 2015, edição Samantha Busnello 2017

\subsection{Ocupação e apropriação do parque pelos usuários}

Para compreender os conflitos internos que caracterizam o Eco Parque como um espaço excludente, é preciso entender e conhecer as pessoas que estão apropriando o espaço e a forma como o ocupam (ZEISEL, 2006). O espaço do parque é projetado e pensado para escala humana, apesar todas as deficiências de infraestrutura pode ser considerado humanizado pois está sempre com usuários em seu espaço. Embora o gerenciamento do parque direcione os atores para alguns tipos de usos, os usuários apropriam se do espaço da forma que lhes interessa melhor, por vezes não seguindo as diretrizes de gerenciamento e infraestrutura do parque.

O clima ambiental e o microclima formado no espaço do parque onde predominam os ventos frios e úmidos, com poucas áreas de incidência solar faz com que o tempo propício para ocupações mais intensas sejam nas estações quentes: primavera e verão, ou nos dias mais quentes das estações frias. Nos dias frios o movimento no parque é fraco, contudo algumas pessoas usam o espaço, principalmente as que praticam atividades físicas. 
A topografia e massa vegetativa influenciam na apropriação do espaço pois o parque apresenta extremos opostos de declive e concentração de árvores na face sul e face norte. O lado norte do local apresenta muito declive e uma massa vegetativa muito densa, desfavorecendo a concentração social, sendo usada só para a pista de caminhada, apenas com um fluxo do pessoal que está praticando corrida/caminhada. A concentração de convívio social acontece na parte plana, que apresenta mais incidência solar durante o dia, e onde estão todos os espaços de permanência.

A tipologia de usuários do parque é muito diversificada: homens, mulheres, adolescentes, crianças, idosos. Possivelmente o fato do local ser um dos únicos espaços públicos da cidade facilita essa alta gama de usuários. Contudo o gerenciamento do parque proíbe e inibe a comercialização de qualquer tipo de produtos no espaço, abrindo exceção unicamente para em eventos promovidos pelo poder público. Esse tipo de proibição abrange também a presença de moradores de rua, que são impedidos de frequentar o local pelos guardas, pelas grades de segurança e horários de funcionamento do espaço. Não existe uma classe social dominante que ocupe o parque, os usuários pertencem a uma classe mais baixa até uma classe mais elevada, pessoas vulneráveis economicamente não são observadas do no espaço. (GEHL, 2009)

Constando o espaço nota-se que os usuários usam o local para 3 atividades bem distintas: lazer, atividade física, passagem. Dessa forma fundamentado em observação e entrevistas denota se grupos distintos baseados na forma de ocupação e uso do parque. (ZEISEL, 2006). Além dos 3 grupos distintos percebe se usuários que frequentam o local por períodos mais breves, menos frequentes ou ainda para uma atividade não correspondente a nenhuma outra observada no parque, usando um espaço não apropriado pelos grupos. O autor Duneier (2000) trata esses movimentos como mancha e pedaço. O pedaço trata se de conhecidos e amigos de academia que se encontram para praticar exercícios físicos no final da tarde, apresenta uma frequência de uma a duas vezes por semana. A mancha trata se trabalhadores do entorno que no horário de almoço frequentam o espaço para interação social breve, apresenta frequência de duas a três vezes por semana.

\subsection{Grupo 01}

O grupo 01 é formado pelos trabalhadores e outras pessoas que usam o parque apenas como passagem, não permanecem no espaço por muito tempo, tratam se de moradores e trabalhadores dos bairros adjacentes ao parque, sendo a grande maioria de classe baixa ou média, dados recolhidos em um espaço amostral de 40 entrevistas. Frequentam o parque nos horários de 07:00 as 08:00 e das 17:30 as 19:00 horas de Segunda a Sexta, nesses horários o fluxo desse grupo é intenso. Em entrevistas alguns atores desse grupo relatam levar as crianças para brincar no final de semana no espaço do parque. Esse grupo, com exceção dos poucos pais que levam os filhos brincar no espaço, usam apenas uma parte da pista de caminhada. A faixa etária desse grupo concentra-se entre 20 a 40 anos. 


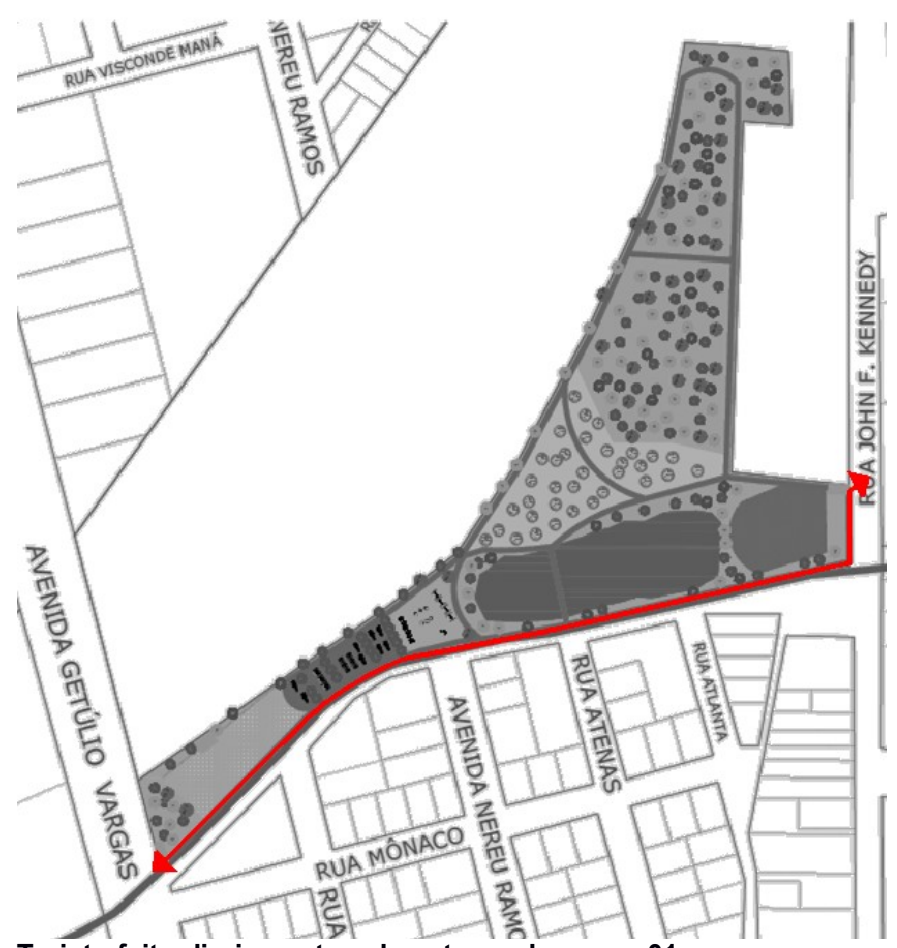

Trajeto feito diariamente pelos atores do grupo 01

Fonte: Prefeitura Municipal de Chapecó, 2016, edição Samantha Busnello, 2017

Se relacionam com o espaço público como espaço de trajetória sem permanecer no espaço por muito tempo, a interação social acontece apenas entre colegas que os acompanham nas horas de folga ou ida e volta ao trabalho, não interagem com outros atores que usam o parque para outros usos. A relação do espaço com o grupo é muito limitada para eles o parque significa um trajeto facilitado pelo desenho e implantação das vias. Contudo questionam a questão de não poder fazer trajetos diferentes pelo parque só ter dois acessos.

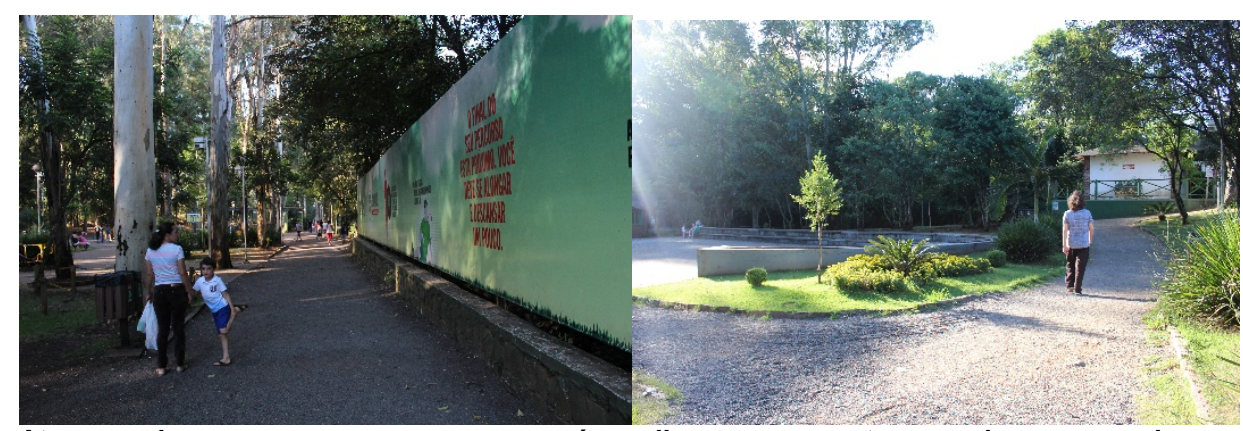

Ator usando o parque como passagem após realizar compra e ator usando o espaço do parque como trajeto para trabalhar. Fonte: Samantha Busnello, 2017

\subsection{Grupo 02}

O grupo dois é formado por atores praticando exercícios físicos, por contato com a natureza ou por não gostar de atividades físicas internas. Tratam-se de pessoas de idades diversificadas, desde 15 anos a idosos. É o maior grupo observado no espaço, essas pessoas frequentam o espaço influenciadas pelo gerenciamento e conceito do parque: a prática de esportes. Observa se esse grupo apropriando se do espaço durante todo o dia, mas de uma forma mais intensa entre as 07:00 as 09:00 e das 14:00 as 19:00 horas, nos finais de semana, durante a semana o fluxo é intenso a partir das 17:00 horas, em dias de frio ou chuva a intensidade diminui drasticamente ficando muito fraca. A faixa de renda desse grupo analisada pelas entrevistas é entre classe média e alta, dados recolhidos em um espaço amostral de 40 entrevistas. Esse grupo é o que usa o espaço físico do parque com maior apropriação, ocupando a maior parte do lugar. Concentram de forma dispersa, deslocando se por todo o trajeto da pista de caminhada, usam a academia e mobiliários para a prática de ginástica, observa se que em alguns momentos apropriam se também do espaço de exposições e anfiteatro aberto para a prática de algumas atividades físicas. 


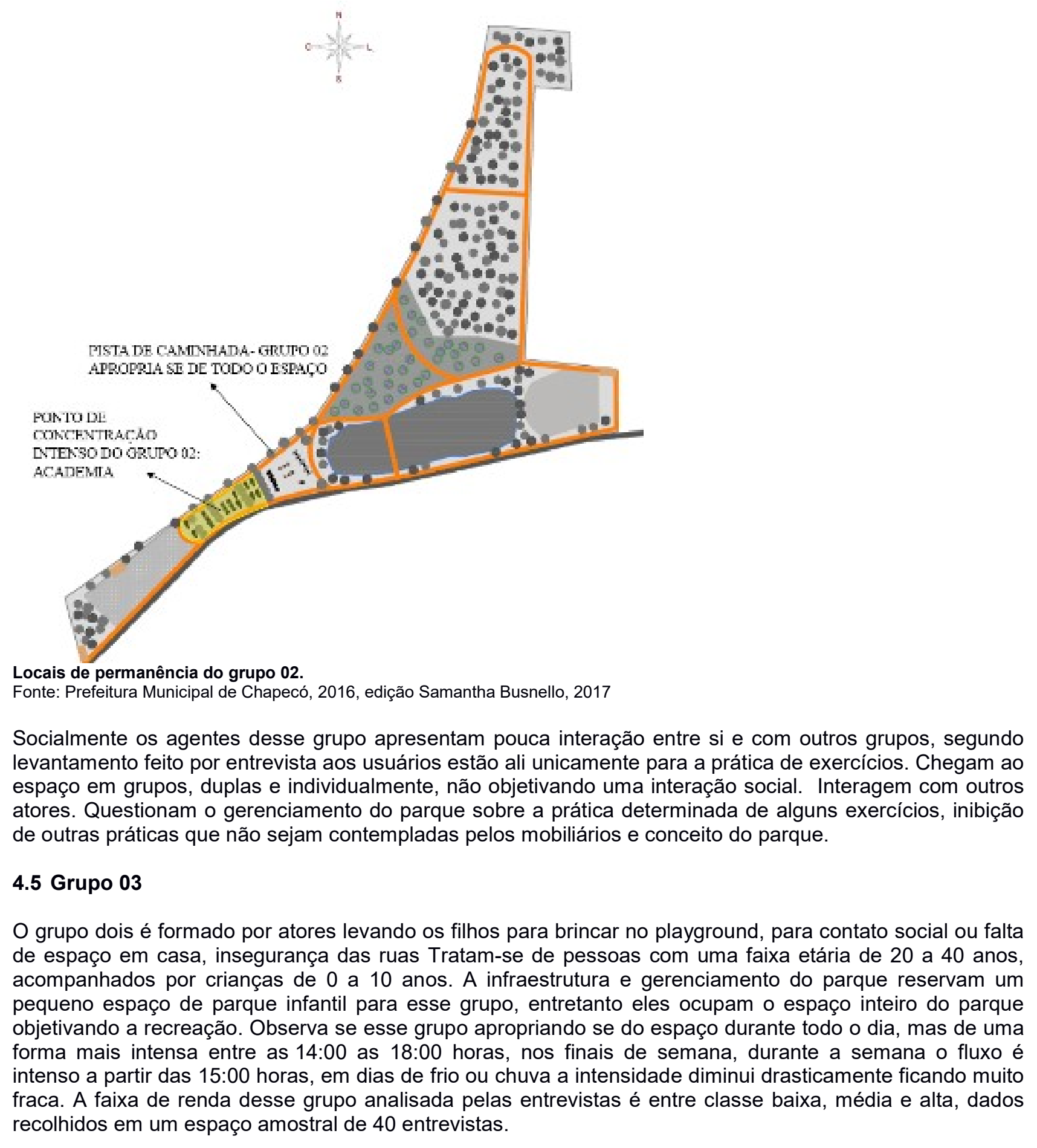




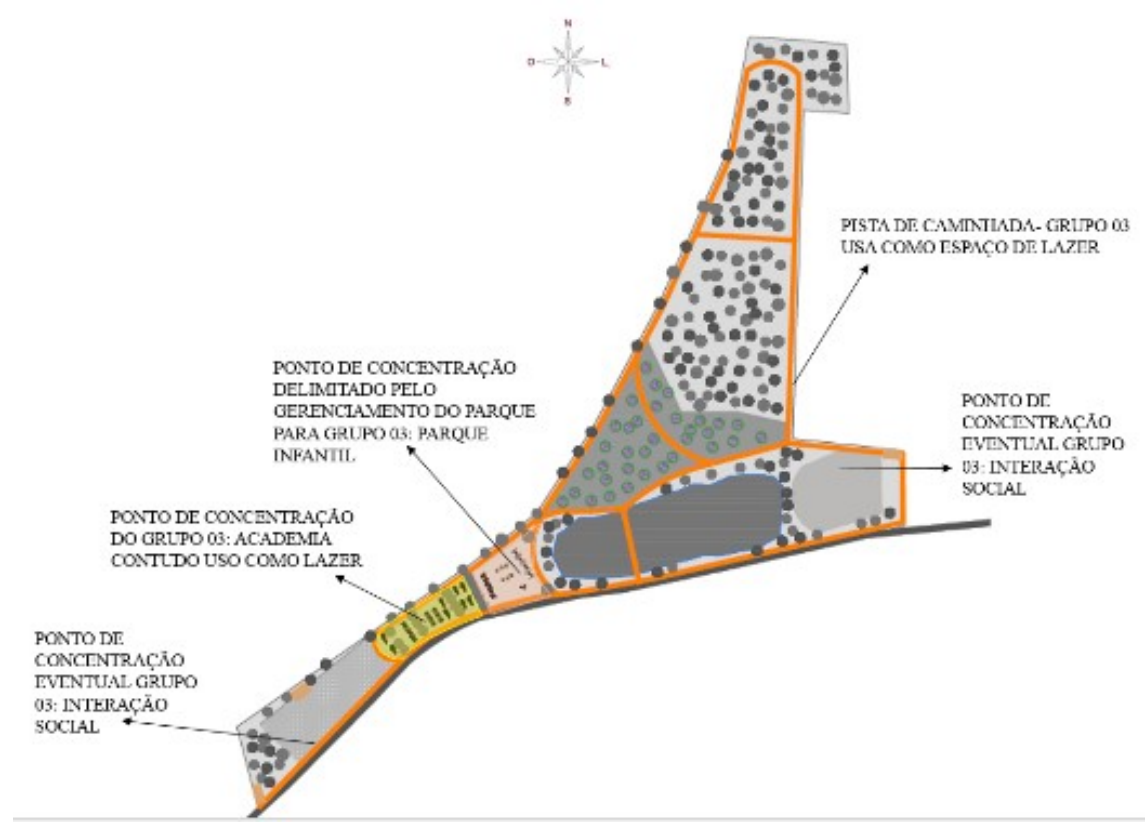

Locais de concentração do grupo 03.

Fonte: Prefeitura Municipal de Chapecó, 2016, edição Samantha Busnello, 2017

Esse grupo usa o espaço físico do parque contrariando todas as regras de gerenciamento e limites físicos do local. Concentram no parque infantil contudo não ficam limitados a esse espaço. As crianças usam trajeto completo da pista de caminhada, a academia e mobiliários, do espaço de exposições e anfiteatro aberto para brincar e os pais usam os mesmos espaços para tomar chimarrão e conversar. É o grupo que se apropria do parque mais intensamente e o que usa todos os seus mobiliários e espaços para interações sociais.
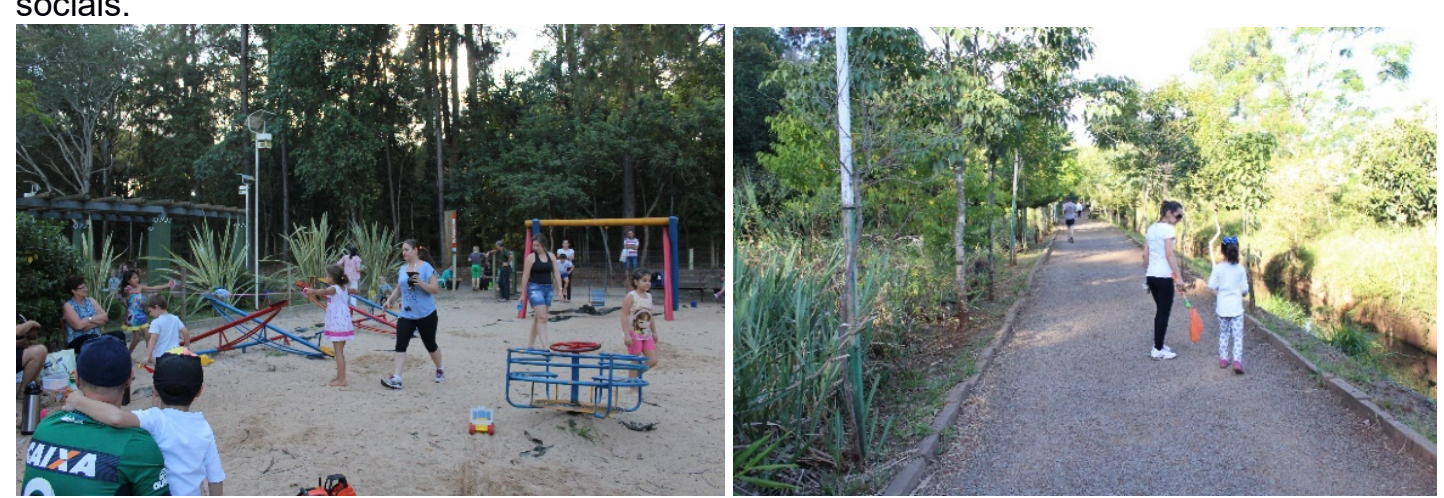

Grupo 03: pais e crianças no Fonte: Samantha Busnello, 2017

Socialmente os atores desse grupo se relacionam independente de idades e classe social. Algumas crianças e mães se encontram unicamente no espaço para interação social, criaram relações de amizade e a cultivam apenas dentro do parque sem encontros externos. Questionam o gerenciamento sobre o espaço ser muito limitado para recreação, contudo é o único grupo que apropria o parque por vontade própria, buscando a recreação além do playground as crianças brincam em todo o ambiente, mesmo nos não determinados pela gestão do parque.

\section{O PARQUE COMO ESPAÇO EXCLUDENTE E AS FRONTEIRAS INVISÍVEIS}

O espaço público reproduz as diferentes relações da sociedade hierarquizada que vivenciamos nos dias atuais, os conflitos do espaço social estão estreitamente conectada com a relação entre os conflitos da estrutura do espaço físico, pois as distâncias existentes no espaço social são retraduzidas no espaço físico (Alex, 2008). Nesse sentido um agente que não está identificado com os usuários ou grupos sociais que apropriam o espaço do Eco Parque instantaneamente é compreendido como não pertencente ao espaço do 
parque, sendo isolado da interação pelos outros atores do espaço ou ainda retirado pelos agentes de segurança do espaço.

A forma diversa como estes diferentes grupos e atores apropriam o espaço em função das práticas sociais evidencia a distinção entre os usuários que estão distantes socialmente apesar de próximos espacialmente. Observa se no espaço uma exclusão social, por atritos entre os grupos de usuários e uma exclusão em virtude do gerenciamento do espaço que impele certos tipos de do local.

\subsection{Exclusão social e conflitos entre os grupos que usam o espaço}

Analisando o espaço os ruídos dos conflitos entre os grupos são praticamente imperceptíveis, observa se um grupo homogêneo e padrão apropriando o espaço. Contudo uma análise mais profunda mostra um grande atrito entre os grupos que estão no espaço, mais especificamente entre os atores do grupo 01 versus os atores do grupo 02 e entre os atores do grupo 03 versus os atores do grupo 02 que resulta na exclusão de alguns agentes dos próprios grupos do espaço do parque.

Entendendo os efeitos da apropriação do espaço por esses grupos distintos nota-se uma exclusão social de outras tipologias que atores que Minton (2006) chama de Pontos Quentes do espaço público: os atores que frequentam o espaço pertencem a uma classe social padrão que por consequentemente afasta outros usuários de diferentes categorias socais.

\subsubsection{Grupo 01 x Grupo 02}

Nos dias com clima favorável a apropriação do espaço a apropriação do espaço para a prática de esportes é muito intensa desde as primeiras horas da manhã, fato que coincide com o fluxo do grupo 01 que está deslocando se pelo parque nesses momentos para chegar até o trabalho. $O$ atrito se cria pois o espaço da pista de caminhada é limitado e as velocidades dos fluxos de movimentação dos dois grupos são diferentes e geralmente opostos: enquanto o sentido de deslocamento predominante do grupo 01 é da Rua John Kennedy para a Avenida Getúlio Vargas enquanto o fluxo de quem está praticando esportes é no sentido contrário. Resultando em uma área de atrito na face sul da pista de caminhada.

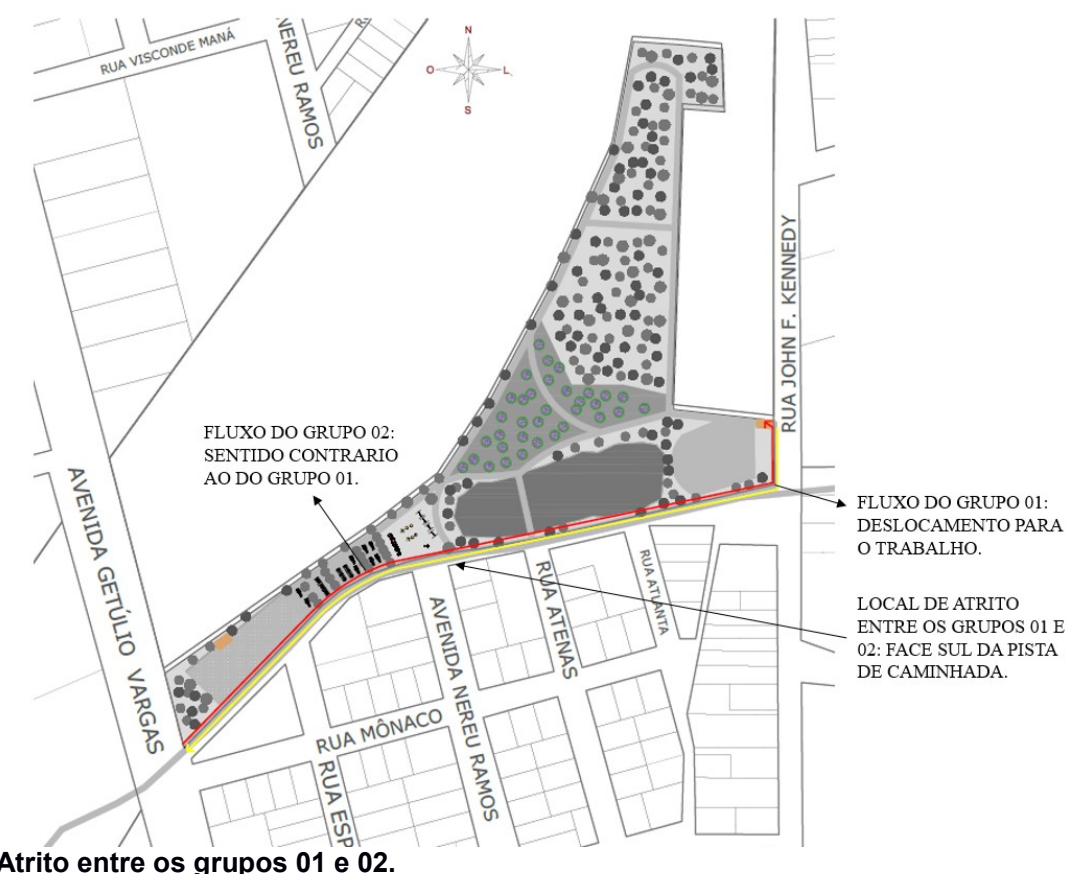

Atrito entre os grupos 01 e 02.

Fonte: Prefeitura Municipal de Chapecó, 2016, edição Samantha Busnello, 2017

Esse conflito entre a tipologia de uso no mesmo horário dentro do espaço parque resulta na desistência de alguns atores do grupo 02 de usar o espaço para praticar exercícios físicos, buscando a Avenida Getúlio Vargas para a prática. A Prefeitura Municipal de Chapecó desenvolve algumas atividades buscando incentivar a prática de exercícios físicos no espaço paradoxalmente uma corrida organizada para o espaço interno do parque teve que ser transferida para a rua no momento em que aconteceria pelo, início da manhã por conta do conflito de números de atores do grupo 01 no espaço do parque no dia e do alto número de praticantes da corrida. 
A exclusão resultante desse conflito afasta os usuários que buscam o espaço do parque para praticas que o conceito do próprio parque oferece. Socialmente o afastamento acontece por divergência de usos e por falta de espaço físico para abarcar os dois grupos no mesmo horário. A tensão se faz presente unicamente nesse momento, se manifesta de forma imperativa ao fazer os atores do grupo 02 procurarem outros locais para praticas que deveriam ser feitas dentro do parque em face a ao grupo 01 que usa o espaço para uma prática não contemplada no projeto do espaço: a passagem.

\subsubsection{Grupo 03 x Grupo 02}

Nos finais de semana os fluxos dos grupos 02 e 03 são muito intensos, as pessoas praticando exercício físico em toda a área do parque e as famílias brincado com as crianças além dos limites do espaço do parque infantil. $O$ atrito entre os grupos surge além da alta concentração de indivíduos dos dois grupos mas também pela interferência dos atores do grupo 03 nos espaços delimitados para o uso predominantemente dos atores do grupo 02.

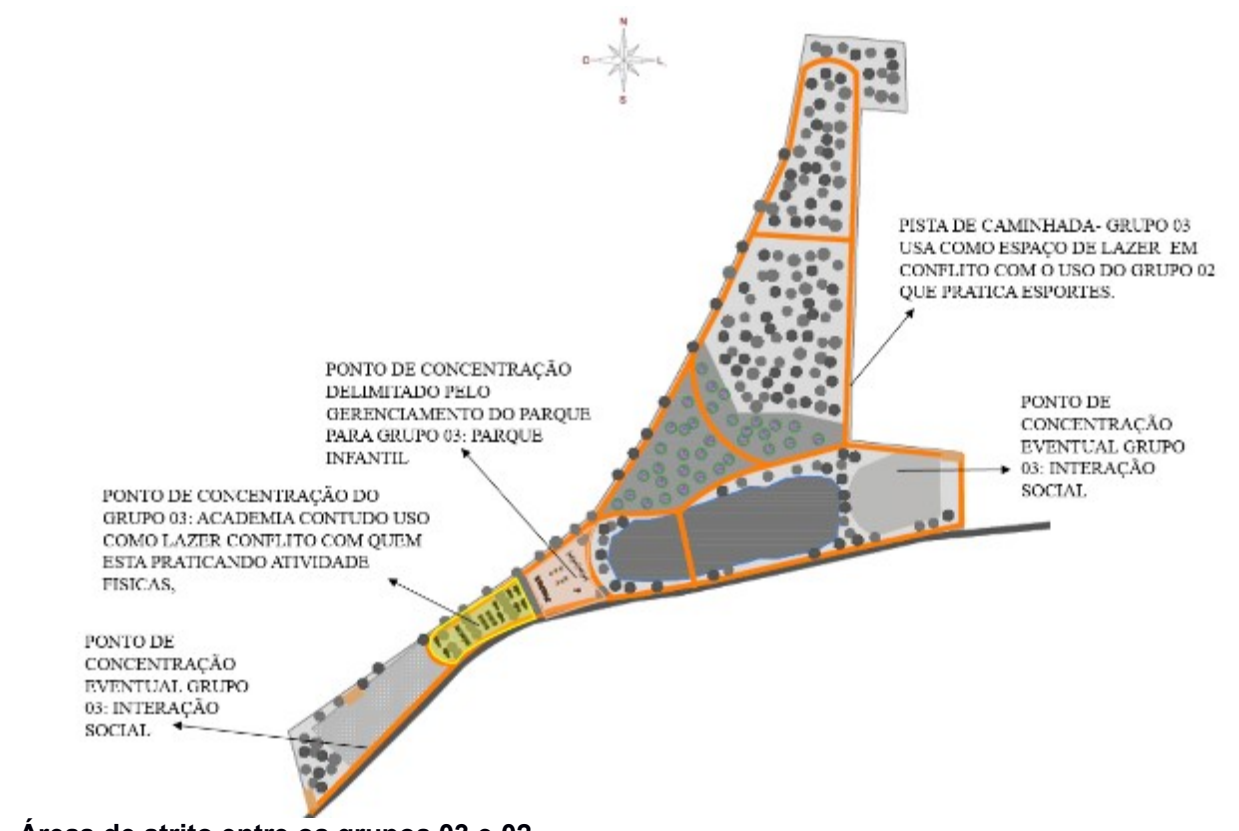

Áreas de atrito entre os grupos 03 e 02.

Fonte: Prefeitura Municipal de Chapecó, 2016, edição Samantha Busnello, 2017

O espaço que o parque destina para as crianças e as famílias interagirem é pequeno e limitado resultando na busca desses atores em outros locais para socializarem. O espaço mais procurado pelas crianças para brincar depois do parque é a academia ao ar livre, cujo local é o mais procurado também pelos idosos para a prática da ginástica por causa do mobiliário ali presente. Nesse conflito os idosos, atores do grupo 02 , não buscam outros lugares para praticar exercícios, terminam por desistir de frequentar o parque permanecendo em casa. Na concepção do grupo 02, as crianças do grupo 03 além de ocuparem os mobiliários para brincar não permitem o uso dos mesmos pelo grupo 02, pois não compreendem a dinâmica do local e permanecem por tempo excessivo usando o mobiliário. Outro fator decisivo para afastar alguns usuários do grupo 02, nesse ponto independente de faixa de idade, é o barulho e bagunça produzidos pelas crianças do grupo 03

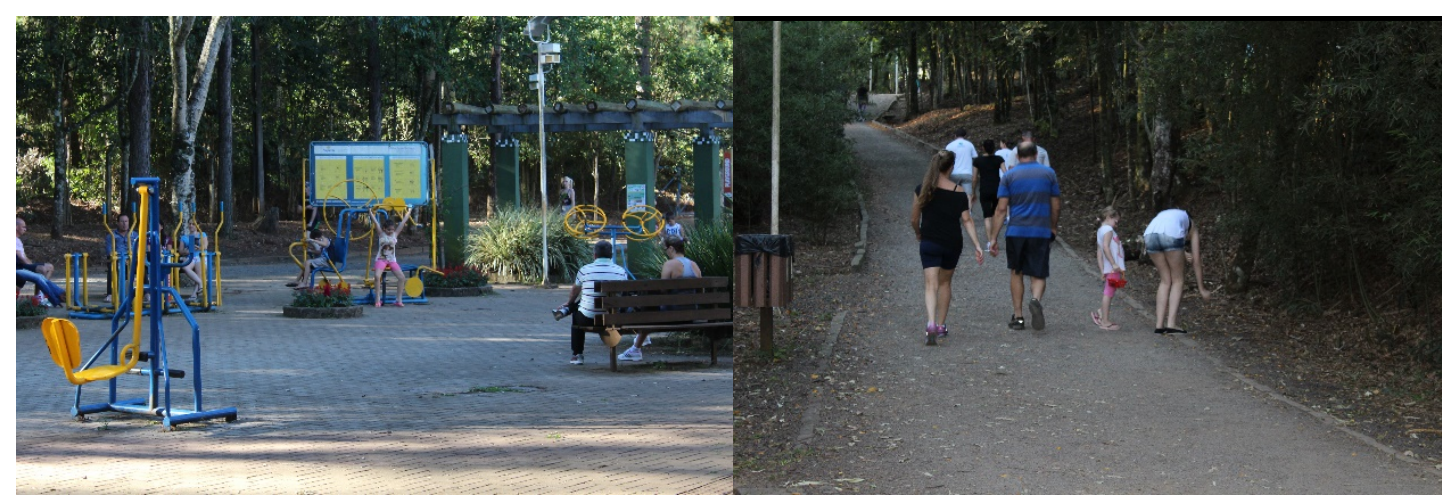


Crianças usando o espaço da academia de ginástica para brincar enquanto idosos aguardam para usar o espaço. Crianças brincado na pista de caminhada.

Fonte: Samantha Busnello, 2017

Os atores do grupo 02 que usam exclusivamente a pista de caminhada, argumentam que as crianças atrapalham o ritmo dos exercícios pois usam o espaço para brincar obstruindo o fluxo e por vezes interrompendo a prática de quem está na pista. Ao contrário dos atores do grupo 02 que não usam mais o espaço do parque, esses agentes mais jovens buscam outros espaços para a prática da caminhada e corrida nos dias em que o parque está apropriado por um número elevado de atores do grupo 03 . Desse conflito resultam então dois tipos de exclusão: a exclusão dos agentes idosos do grupo 02 que não buscam mais o espaço do parque e a exclusão temporária dos agentes mais novos que buscam outros espaços nos dias em que o grupo 03 predomina no parque.

\subsection{Exclusão social e conflitos causados pelo gerenciamento do espaço}

O gerenciamento do parque, que segundo Carmona (2006), pode ser considerado um supergerenciamento, resulta entre outras coisas na exclusão social. Iniciando pelo conceito do parque que é a de prática de esportes excluindo algumas modalidades de uso, entre elas um grande número de opções de prática de exercícios físicos, inibe a interação social de alguns tipos de atores que realmente não são observados no espaço. Impossibilita o uso do solo para atividades comuns a parques públicos.

Para Santos (2004), a forma como o espaço é gerenciado reflete na realidade da sociedade onde está inserido. O Eco Parque, através da sua gerência reflete uma cidade de tamanho médio que está inserida em um cenário de segregação social. As diretrizes do uso dos espaços ditados pelos órgãos públicos traduzem questões como segurança em excesso e desconfiança de agentes pertencentes a grupos sociais diferentes.

\subsection{Supergerenciamento e exclusão social por meio da segurança}

O sistema de segurança do parque é intensivo e praticado por meio de cercamento, guaritas, guardas de vigilância e horário de funcionamento. O sentimento de desconfiança motivado pela insegurança e pela incerteza do que se pode esperar de agentes individuais ou grupos sociais que não pertencem a mesma realidade dos usuários cria regras imaginarias de quem pode frequentar o local. $O$ parque não inibe efetivamente a presença de moradores de ruas e agentes considerados em risco social, contudo foi presenciado a retirada de um morador de rua do espaço por um dos guardas de vigilância durante a observação.

As grades, portão e horários de funcionamento do espaço selecionam e inibem os tipos de usuários que podem usar o local. Essa segurança e vigilância intensificada segundo Carmona (2006), afasta usuários que não são bem-vistos socialmente pelos outros, esse movimento é notado no Eco Parque ao observar a mesma tipologia de atores no espaço.

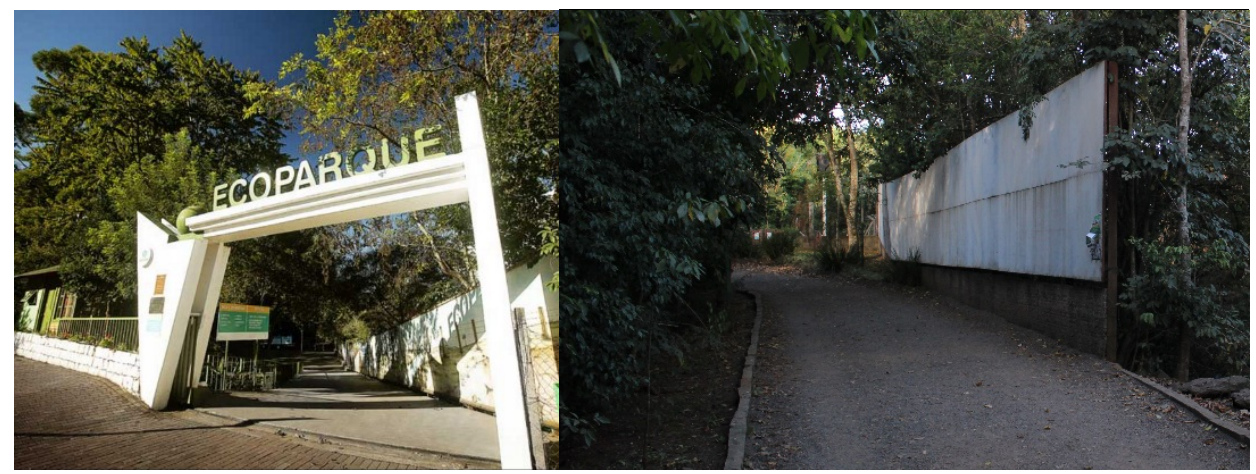

Guarita, portões e cercamento por grades e painéis metálicos no espaço do parque.

Fonte: Samantha Busnello, 2017

A ideia de segurança enquanto conforta os usuários do parque afasta a população mais vulnerável economicamente, que não possui espaços alternativos para frequentar e acaba ficando sem acesso ao espaço público. Novamente nota se o reflexo da separação social da sociedade no espaço público, inibindo o acesso e deixando sem amparo a parcela mais carente da sociedade.

\subsection{Supergerenciamento e exclusão social por meio da infraestrutura}


O conceito do parque dita as diretrizes de uso e infraestrutura, com a definição de local para a prática de exercícios físicos o espaço não atende a própria ideia conceitual. A gestão do parque inibe usuários de praticar modalidade de esportes diferentes das predestinadas através da proibição implica e falta de infraestrutura. Ciclismo, patinação, entre outros esportes não são permitidos no espaço que contempla estrutura apenas para caminhada, corrida, ginástica e eventualmente alguma prática em grupo. Essa condição exclui do espaço uma tipologia de usuários que praticam essas modalidades, novamente forçando os atores a buscar locais alternativos como a rua.
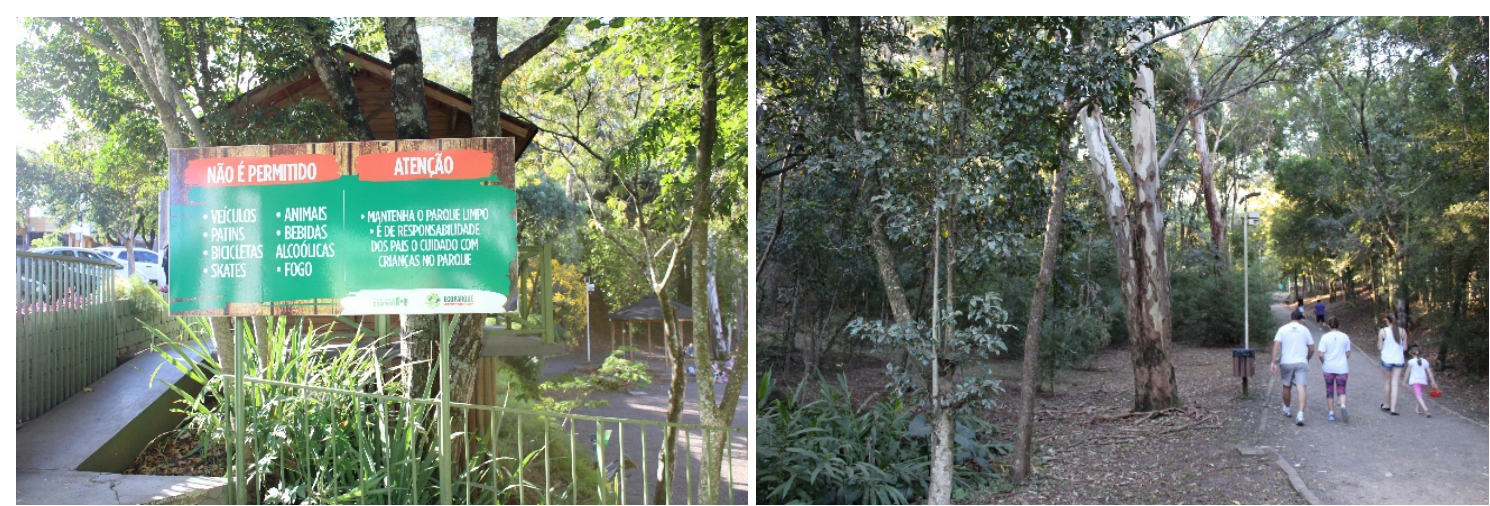

Placa com diretrizes de uso do espaço e usuários (grupo 02 e 03) usando apenas o espaço da pista de caminhada sem acessar o resto do espaço.

Fonte: Samantha Busnello, 2017

Usos comuns a parques públicos não são observados no espaço do Eco Parque, como a permanência no espaço com animais de estimação, piqueniques, entre outros. O local apresenta poucos espaços na parte plana que poderiam receber atividades distintas das permitidas pelo gerenciamento, contudo esses locais estão cercados impossibilitando o acesso dos usuários e novamente selecionando apenas os atores que dispõem se a usar o parque dentro das limitações permitidas.

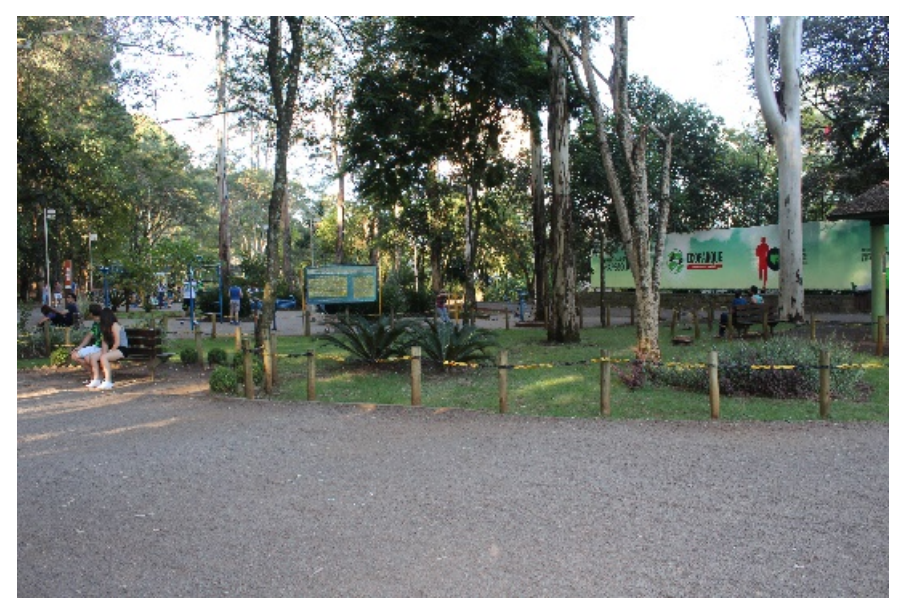

Espaços planos e com vegetação, que poderiam ser usados para lazer, cercados impedindo o acesso dos usuários. Fonte: Samantha Busnello, 2017

A exclusão social mais gritante dentro do espaço é com as pessoas que apresentam dificuldade de mobilidade. A infraestrutura do local não apresenta em nenhum momento facilidade de acesso para pessoas em cadeiras de roda, com carrinhos de bebê, com deficiência visual. As vias, espaços e mobiliário não possuem pavimentação, sinalização e condições mínimas e adequadas para receber essa parcela da população. 


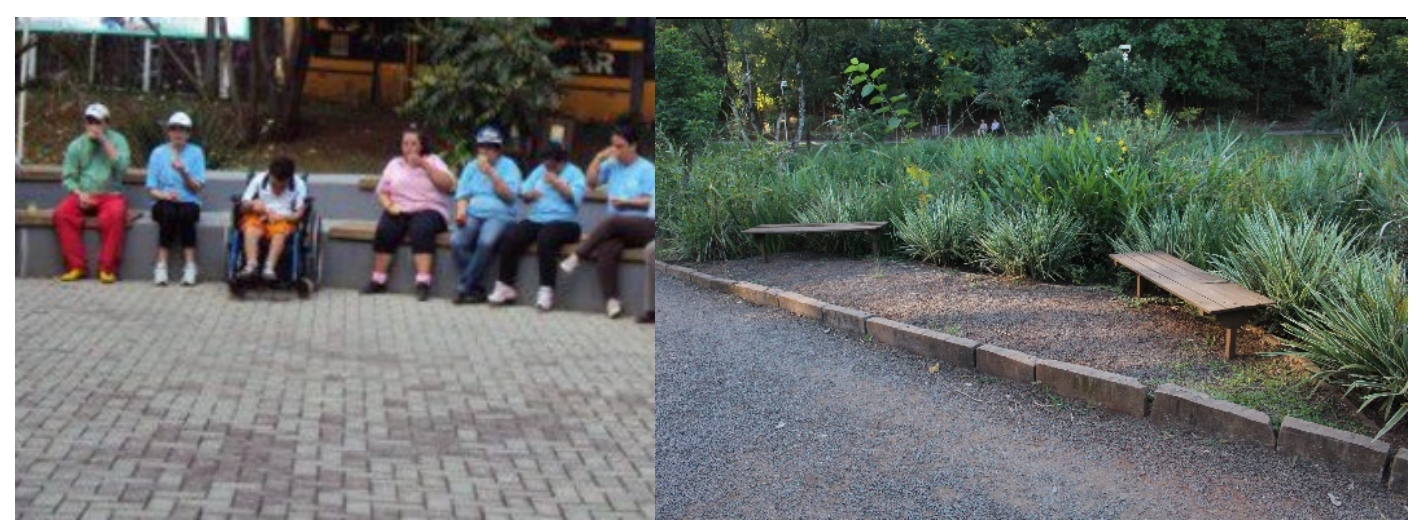

Cadeirante esperando enquanto grupo escolar realiza atividades no interior do espaço. Via e mobiliários sem condições de uso por pessoas com necessidades especiais de locomoção.

Fonte: Samantha Busnello, 2017

As pessoas com necessidade especiais de locomoção, juntamente com os menos favorecidos financeiramente ficam sem opções de espaços públicos para a apropriação na cidade, enquanto os outros agentes excluídos por diretrizes de uso do parque buscam espaços de apropriação nas ruas ou em espaços privados. O Eco Parque que deveria ser um espaço inclusivo e abranger grande parte da população da cidade exclui a maior parcela de cidadãos e setores sociais de estarem presentes em seu espaço e inibe o acesso dessas pessoas a um dos principais atrativos da cidade.

\section{CONSIDERAÇÕES FINAIS}

A exclusão social dentro do parque cria fronteiras invisíveis no espaço. A ideia de fronteira corresponde a um terceiro entre dois espaços distintos como um vácuo, símbolo narrativo de intercâmbios e encontros. Pode ser compreendida também como um espaço inatingível que não se materializa entre limites concretos entre agrupamentos sociais distintos, (Mog, 2017). A partir do cotidiano no espaço público as fronteiras se transformam, surgem ou desaparecem de acordo com as diferentes relações que surgem no tempo e no espaço entre grupos sociais e conflitos.

Observando as relações dinâmicas dentro do espaço do Eco Parque, nota se de forma sutil a construção do conceito de fronteiras nos espaços públicos formadas pelas relações sociais e pelas diretrizes de gerenciamento do espaço. Especialmente o grupo 02 constrói fronteiras com o grupo 01 e 03 ao passo que o atrito criado pela apropriação de um espaço dentro do parque que deveria servir exclusivamente para a prática de esportes por usuários com outras tipologias de usos inibe e afasta do local os agentes do grupo que pelo conceito do espaço deveria predominar. Essas fronteiras construídas pelos atritos das relações sociais culminam exclusivamente na evasão do espaço pelos agentes que se sentem incomodados evidenciando a exclusão social do espaço.

O gerenciamento do espaço crias as fronteiras ao inibir e afastar tipologias de usuários, mas diferente dos atritos sociais essas fronteiras servem para controlar o espaço segregador que paradoxalmente deveria ser democrático. A principal fronteira criada pelo gerenciamento do parque é a exclusão das pessoas com necessidades especiais de locomoção que não são contempladas no local e quando tentam quebrar essa barreira para usar o espaço não obtém sucesso pela deficiência de infraestrutura. A exclusão social implícita das pessoas com baixa renda ou em situação de risco social pode ser compreendida como um conjunto resultante das diretrizes do espaço e da inibição do grupo social padrão que frequenta o espaço, também resultante das limitações impostas pelo gerenciamento do espaço.

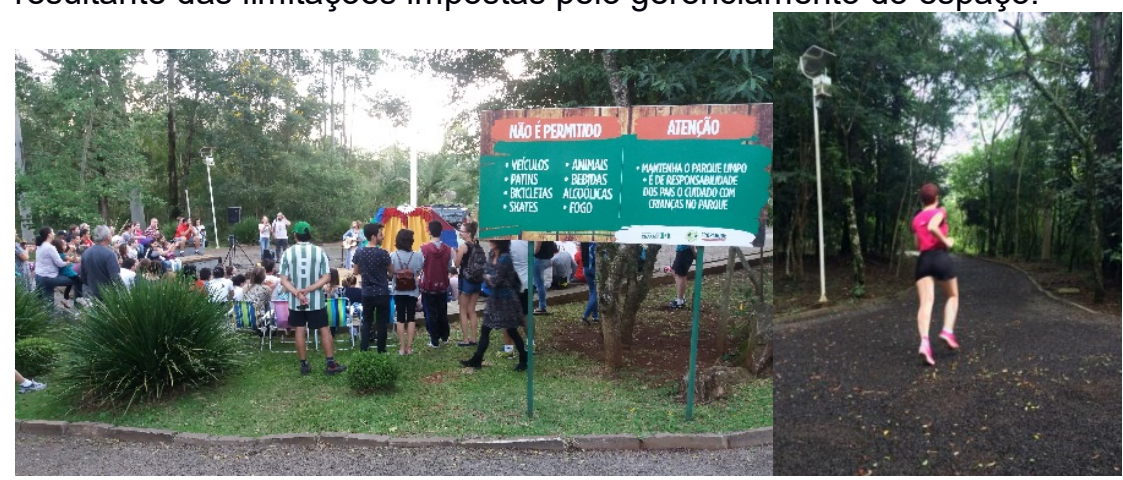


Usuários quebrando fronteiras impostas pelo gerenciamento do parque. Usuário padrão seguindo as barreiras impostas pelo gerenciamento

Fonte: Samantha Busnello, 2017

Quebrar as barreiras invisíveis impostas dentro do espaço do parque para os agentes externos ao grupo de usuários pode ser considerado um ato improvável ao passo que o Eco Parque não apresenta meios de acesso e integração. As barreiras criadas entre os grupos são quebradas apenas pelos atores do grupo 03, especificamente as crianças, que não importam se com as limitações físicas e morais e usam o espaço buscando a recreação.

A exclusão social tão presente na sociedade se faz presente no espaço público e não é imposta por um grupo específico mas sim pela reprodução das fronteiras invisíveis que encontramos no cotidiano. O Eco Parque como espaço público tem pertinentes fronteiras construídas mostrando se um espaço segregador e excludente que falha consideravelmente no papel democrático de acesso à cidade. As fronteiras construídas dentro do parque no dia a dia manifestam se complexas e com caráter de difícil transgressão para que a exclusão social seja ao menos amenizada.

Ao observar um determinado espaço público e compreensível que as interações entre grupos sociais problematiza a determinação do espaço. A construção e desconstrução das relações reflete de forma direta na dinâmica relação entre apropriação do espaço e deslocamento através do lugar. Desta forma as barreiras invisíveis são traçadas pelos conflitos criados entre pontos de encontro entre as apropriações por diferentes grupos sociais e os deslocamentos sucessivos.

Apesar de o Eco Parque estar aberto a todos, os conflitos existes estruturam-se de forma a garantir uma área privilegiada da cidade apenas a uma parcela de pessoas, resultantemente acaba reproduzindo na estrutura do espaço social um distanciamento social marcado por fronteiras invisíveis que delimitam os diferentes locais apropriados em função dos diferentes grupos de usuários. Em outras palavras embora o espaço seja público, o acesso ao parque não é universal, socialmente e fisicamente falando. O principal fator resultante no espaço do parque é a exclusão de uma parte pontual da população da cidade: pessoas com necessidades especiais de locomoção, pessoas em risco social, pessoas com baixas condições financeiras e até mesmo alguns usuários do próprio espaço para outros locais da cidade.

No espaço do Eco Parque, entre a maioria dos frequentadores os conflitos são nítidos ao passo que uma resolução sem alterar o projeto e infraestrutura do espaço parece inalcançável. O conflito mais notório é do grupo 03, ou seja, as crianças que apropriam todo o espaço do parque em detrimento aos outros atores do espaço. Paradoxalmente esse grupo é o que mais se beneficia do espaço demostrando que embora nem sempre as diretrizes ditadas pelo gerenciamento do espaço sejam as mais adequadas para o seu uso, ou ainda para os atores do local, estes mesmos adaptam o espaço público para o fim que mais lhes convém.

Analisando todos os conflitos do espaço, as barreiras invisíveis formadas conclui-se que o Eco Parque reflete a realidade da maioria dos espaços públicos atuais: o espaço público sendo usado como espaço de exclusão. Contrariando o pressuposto utópico do espaço público ter acessibilidade universal e atender a toda a sociedade o parque é de uso exclusivo a grupos bem definidos, não exercendo o papel de espaço democrático para sociedade.

\section{REFERÊNCIAS BIBLIOGRÁFICAS}

ALEX, Sun. Projeto da praça: convívio e exclusão no espaço público. São Paulo: SENAC, 2008

CARMONA, Matthew; TIESDELL, Steve (editores). Urban Design Reader. Oxford: Elsevier, $1^{\mathrm{a}}$ edição, 2007.

CARMONA, M. et al. Public Places - Urban Spaces. [s.I.] Taylor \& Francis, 2012.

DUNEIER, M.; HASAN, H.; CARTER, O. Sidewalk. New York: Farrar, Straus and Giroux , 2000

GEHL, J. La humanización del espacio urbano. La vida social entre los edificios. Barcelona: Editorial Reverté, 2009.

GEHL, J. SVARRE, B. How to study public space. Washington: Island Press, 2013.

INNERARITY, D. O novo espaço público. Lisboa: Tex to Editores, 2010.

JOVCHELOVITCH, S. Representações sociais e esfera pública. A construção simbólica dos espaços públicos no Brasil. Petrópolis, RJ: Vozes, 2000. 
JACOBS, J. Morte e vida de grandes cidades norte-americanas. São Paulo, Martins Fontes, 2000.

LYNCH, K.; HACK, G. Site Planning. 3rd Ed. MIT, 1984.

MAGNANI. J. G. C. De perto e de dentro: notas para uma etnografia urbana. In: Revista Brasileira de Ciências Sociais. Vol. 17, n. 49, junho, 2002

PALLASMAA, J. Los ojos de la piel. La arquitectura y los sentidos. Barcelona: Gustavo Gili, 2006

SANTOS, M. A natureza do espaço: técnica e tempo. Razão e emoção. 4.ed. São Paulo: Edusp, 2004.

SANTOS, N. F.; VOGEL, A.; MELLO, M. A. S.; PAVEL, P.; LIMA, M. A.; NUNES, Z. C. M. Quando a rua vira casa: a apropriação de espaços de uso coletivo em um centro de bairro. $3^{\mathrm{a} e d .}$ São Paulo: Projeto, 1985.

THIBAUD, J.P. Ambiências de passagem - figuras, condutas, medidas. In: DUARTE, R. C.; VILLANOVA, R. Novos olhares sobre o lugar: ferramentas, metodologias, da arquitetura àantropologia. Rio de Janeiro: ContraCapa: FAPERJ, 2013.

ZEISEL, J. Inquiry by Design. Environmental/Behavior/Neuroscience in Architecture, Interiors, Landscape, and Planning. New York: W. W. Norton \& Company, Inc., 2006.

URIARTE, U. M. Olhar a cidade: contribuições para a etnografia dos espaços urbanos. In: Ponto Urbe, 13, 2013. 